\title{
Breve relación de las misiones de la Patagonia hecho el 29 setiembre de 1887. El militarismo patagónico. El General Villegas por el salesiano Antonio Ricardi
}

Brief account on Patagonia missions done in 29 September 1887. The Patagonian militarism. General Villegas by Salesian priest Antonio Ricardi

\section{María Andrea Nicoletti y Iván Ariel Fresia}

\section{(2) OpenEdition}

Journals

\section{Edición electrónica}

URL: http://journals.openedition.org/corpusarchivos/688

DOI: 10.4000/corpusarchivos.688

ISSN: 1853-8037

\section{Editor}

Diego Escolar

\section{Referencia electrónica}

María Andrea Nicoletti y Iván Ariel Fresia, « Breve relación de las misiones de la Patagonia hecho el 29 setiembre de 1887. El militarismo patagónico. El General Villegas por el salesiano Antonio Ricardi », Corpus [En línea], Vol 4, No 1 | 2014, Publicado el 30 junio 2014, consultado el 30 abril 2019. URL: http://journals.openedition.org/corpusarchivos/688; DOI : 10.4000/corpusarchivos.688 


\section{Breve relación de las misiones de la Patagonia hecho el 29 setiembre de 1887. El militarismo patagónico. El General Villegas por el salesiano Antonio Ricardi}

Brief account on Patagonia missions done in 29 September 1887. The Patagonian militarism. General Villegas by Salesian priest Antonio Ricardi

María Andrea Nicoletti y Iván Ariel Fresia

\section{NOTA DEL EDITOR}

Fecha de recepción del original: 10/03/2014

Fecha de aceptación para su publicación: 12/06/2014

\section{Introducción}

1 Un documento sobre las misiones salesianas escrito en la etapa inicial de la tarea evangelizadora y de conquista de la Patagonia, permite adentrarse no sólo en la metodología y acción misionera, sino en las relaciones y los complejos vínculos que a través de esa tarea sostuvieron los actores sociales involucrados. Estas relaciones asimétricas entre misioneros, militares y pueblos originarios, fueron atravesadas por el poder civil y eclesiástico en un contexto histórico en tensión entre ambas instituciones (fines del siglo XIX), que desató una violencia extrema hacia los pueblos originarios.

2 El texto de Antonio Ricardi, escrito en clave de denuncia por el secretario del Vicario Juan Cagliero, relata vejámenes hacia los pueblos originarios y ofensas hacia los miembros de 
la Congregación. Los hechos son narrados en un mismo plano de gravedad, a pesar de ser disímiles y buscan justificar un éxito relativo en la tarea misionera de la Congregación, a causa de una construcción conceptual que realiza su autor al principio del texto y que ilustra posteriormente con los hechos: el militarismo patagónico que encarna en la figura del General Villegas.

Con el fin de comprender el contexto del documento y las relaciones entre los actores sociales mencionados, expondremos brevemente cuáles fueron los planes de evangelización de la Congregación salesiana y sus conceptos teóricos y metodológicos sobre los sujetos a evangelizar, en un contexto signado por la violencia en medio de la conquista de los territorios indígenas de la Patagonia por parte del Estado argentino.

isiones salesianas en la Patagonia se desarrollaron a partir de 1880 con la entrega de la parroquia de Carmen de Patagones que dejaron los religiosos de San Vicente de Paul o lazaristas, convocados por el arzobispo Federico Aneiros (Copello, 1945). Hacia 1875 llegaron los Salesianos de Don Bosco a Buenos Aires, y la rama femenina de la Congregación, las Hijas de María Auxiliadora en 1879. Si bien en un principio los Salesianos se dedicaron a las actividades parroquiales, oratorianas, escolares y de inmigrantes italianos en Buenos Aires, el mandato expreso de su fundador, Juan Bosco, era el de evangelizar la Patagonia.

Durante esta etapa el inspector salesiano Bodratto, solicitó al gobierno la concesión y administración exclusiva del territorio patagónico, para la implementación de colonias que en diez años, señalaba el inspector, "se colocarán en iguales condiciones que los demás pueblos argentinos; y los misioneros durante su administración levantarán siempre en sus pueblos a la vez que la cruz de la civilización la bandera nacional" (Archivio Salesiano Centrale, Carta de Don Brodatto a Don Bosco, Buenos Aires 26 de enero de 1880).

6 Esta solicitud y los planes diseñados por Juan Bosco, habían sido elaborados en base al conocimiento teórico sintetizado en un informe presentado al Colegio Propaganda Fide por él mismo y su secretario Julio Barberis (Bosco y Barberis, [1876] 1988 y Ceria, 1958, t. III) ${ }^{1}$, en el que recopilaron textos circulantes de la época sobre la Patagonia y sus habitantes (Nicoletti y Navarro Floria, 2002, pp.113-144).

7 En el plano misionero Don Bosco apuntaba a establecerse en zonas consideradas de frontera para ingresar cautelosamente, observando el mejor modo de hacerlo y permitiendo que los indígenas se acostumbraran a la presencia misionera con el ingreso de los religiosos a las tribus: "introducirse poco a poco en el desierto de la Patagonia y ganar aquellas tribus abriendo escuelas para sus niños y recogerlos en hospicios y orfanatos" (Bosco y Barberis, [1876] 1988, p.156) ${ }^{2}$. Su objetivo "era contraer relaciones con sus padres por medios de los hijos para que los salvajes se convirtieran por medio de los mismos salvajes" (Archivo Propaganda Fide Carta de Don Bosco al Cardenal Franchi, Torino 31 de diciembre de 1878$)^{3}$ y posteriormente lograr entre ellos vocaciones indígenas. Este proyecto de acercamiento a través de los hijos de los caciques, se puso en marcha, según informaba Cagliero, en Patagones "en el hospicio anexo a la escuela" "con los niños huérfanos indígenas a quienes se les enseña un oficio y música instrumental" (Archivo Propaganda Fide Memoria de Juan Cagliero al Secretario Prefecto, 9 de julio de 1884) ${ }^{4}$ y continuó en otros centros misioneros (Boletín Salesiano 8, 1895) ${ }^{5}$. Los distintos planes misioneros ${ }^{6}$ que aportaron a la construcción del territorio eclesiástico, nos muestran cómo desde el lejano punto de origen del proyecto, en base a la información recolectada y las consideraciones de la Iglesia respecto de la evangelización "ad gentes"', 
se diagramaban las misiones. Su contexto de desarrollo fue en una tierra signada por la violencia entre los pueblos originarios y los nacientes estados argentino y chileno, que buscaban apropiarse de esos territorios y mantener el poder de la Iglesia bajo su dominio (Nicoletti, 2010).

En el plano administrativo, su idea inicial era implementar misiones salesianas en una Patagonia "libre y sin ataduras" (Da Silva Ferreira, 1995, p. 24), por lo que Don Bosco gestionó una administración que dependiera directamente del Vaticano: Un Vicariato y una Prefectura apostólica, que fueron erigidas en 1884. A principios del siglo XX el Vicariato apostólico de los Salesianos, comprendía el sur de la provincia de Buenos Aires, y los territorios nacionales de La Pampa central, Río Negro, Neuquén y Chubut ${ }^{8}$. Esta administración contaba con unos 106 mil habitantes en 730 mil kilómetros cuadrados; mientras que la Prefectura (Patagonia chilena, territorio chileno de Magallanes, territorios argentinos de Santa Cruz, Tierra del Fuego e islas Malvinas), tenía menos de quince mil habitantes y una extensión de medio millón de kilómetros cuadrados. El personal salesiano en el Vicariato era 154 personas y en la Prefectura de 93 personas (Salesianos e Hijas de María Auxiliadora) hacia el año 1900 (Carbajal, 1900, pp. V-VI) ${ }^{9}$. Estas administraciones fueron un punto álgido de conflicto entre la Congregación salesiana, la Iglesia argentina y el Estado nacional (Nicoletti, 2010).

El gobierno de Roca con su conjunto de "leyes laicas", mermó considerablemente el poder de la Iglesia que culminó con la expulsión del Delegado Apostólico Matera (Archivo Propaganda Fide Juan Cagliero, Referencia sobre las misiones de la Patagonia, Torino 8 de abril de 1884). Los Salesianos debieron enfrentar la situación directamente con el presidente argentino Julio Roca para defender su proyecto, quien objetó la presencia del Vicario Cagliero como Obispo por ser extranjero y porque no había sido nombrado con el consenso del gobierno. Cagliero, diplomáticamente, optó por salvar la presencia misionera de los Salesianos en la Patagonia, mostrándose como, "Obispo misionero, visitador de nuestras Casas Salesianas y especialmente encargado por los Superiores de aquellos que estaban en la Patagonia", bajo la "autoridad del Arzobispo de Buenos Aires" (Archivo Propaganda Fide, Relación de la visita de Monseñor Cagliero al Vicariato, Patagones 28 de julio de 1884$)^{10}$. La situación de inestabilidad jurisdiccional se terminó de resolver en 1911 con el segundo Rector Mayor salesiano, Miguel Rua a través de su visitador extraordinario Pedro Ricaldone (Archivio Salesiano Centrale, Visita extraordinaria de Pedro Ricaldone,1908, p.2 $)^{11}$, tras arduas negociaciones entre el Vaticano, el gobierno argentino y la Congregación salesiana ${ }^{12}$. Este fue el contexto de conflicto interno entre las agencias eclesiástica y estatal, cuando los Salesianos ingresaron a la Patagonia con el ejército de Julio Roca como Ministro de Guerra en 1879. El escenario al que arribaban presentaba una situación de violencia hacia a los pueblos originarios, que agudizaba aún mas los conflictos latentes ya descriptos.

10 ¿Cuáles fueron los modelos misioneros adoptados ante una situación tan tensa y compleja?

11 Si bien los modelos que desarrollaron en la Patagonia fueron de misiones volantes (modelo llevado a cabo por monseñor Cagliero en la Patagonia continental) y reduccional (a cargo de monseñor Fagnano en Tierra del Fuego), los Salesianos fueron conscientes sobre todo por su experiencia congregacional al establecer colonias agrícolas en Europa (Borrego, 2001, p.145 y Trezzi, 2000, pp. 231-254) ${ }^{13}$, que el proyecto colonizador debía realizarse, idealmente en poblaciones permanentes donde construir parroquias y escuelas: instituciones claves para la "argentinización del territorio". En una evaluación 
que realizaba Cagliero al Colegio de Propaganda Fide, planteaba justamente este tema ante los pobres resultados de las misiones volantes que finalmente establecieron: "multiplicar las residencias fijas para todos los que se han reagrupado en un cierto número de familias" (...) con misioneros residentes". Este modelo más cercano a las reducciones, buscaba que los indígenas abandonaran la "vida nómade" y que el sacerdote pudiera establecerse el tiempo suficiente para que ellos recibiesen el catecismo y los sacramentos necesarios para lograr la "conversión" completa, ya que "las causas de tanto mal se han encontrado en la ignorancia religiosa, la lejanía de los centros de civilización cristiana en contacto con los indígenas" (Archivo Propaganda Fide, Relación quinquenal 1903-1908) ${ }^{14}$.

Los planes misioneros fueron elaborados en términos teóricos, en base a una construcción de alteridad del sujeto de evangelización: la idea del "infiel", que resultó determinante en el acercamiento a los indígenas excluidos del modelo colonial y nacional. Para Don Bosco este concepto entroncaba con la tradición misionera fundada por Bartolomé de Las Casas y José de Acosta en el siglo XVI. Sus puntos fuertes fueron la afirmación de la unicidad del género humano (monogenismo), la defensa de la dignidad intrínseca de todas las personas, y la asignación de la culpa de los "hábitos salvajes" al Demonio (demonización). Esto supuso exculpar a los indígenas de su "naturaleza indómita" y categorizarlos como "infieles", desconocedores de la verdad por ignorancia y no por falta de inteligencia (Bosco y Barberis, [1876] 1988, pp.75, 85 y 115). Este concepto incluía la posibilidad de aprendizaje de cada grupo indígena, de acuerdo a las teorías ambientalistas vigentes en la época. En su informe Don Bosco cita frecuentemente a Alcide d'Orbigny, quien sostiene que los indígenas no sometidos no pueden ser reducidos a la "civilización", o sea a pautas occidentales por "insumisión natural". Esta naturalización de la situación política, es decir, el conceptualizar que la insumisión de los pueblos indígenas del sur responde a leyes de la naturaleza que son, como tales, inmutables, implicaba que los no sometidos nunca se someterían y su destino lógico sería entonces justificado con el exterminio. Conclusiones decisivas para la política de frontera del siglo XIX. De estos dos conceptos Don Bosco sostuvo en su discurso sólo el segundo (civilización y sometimiento), para armar su proyecto misionero-educativo, desechando el primero al que justificó con argumentos teológicos y no antropológicos. En su informe no sólo afirmó que los que se habían sometido se habían "civilizado", sino que también exculpó, en buena medida, a los no sometidos de su mala disposición hacia los "blancos", debido a "la imprudencia y la conducta esencialmente impolítica de los primeros españoles" y a "la conducta de exterminio que aún en la actualidad practica la República Argentina" (Bosco y Barberis, [1876] 1988, p.161). El fundador de los Salesianos inició así un discurso exculpatorio que contiene también importantes elementos teológicos, como la proclividad a la idolatría y la presencia de otro agente externo a ellos y poderoso: el demonio, que opacaba la fe y transformaba al indígena en una víctima de su acción, desterrando así su ignorancia de la fe por naturaleza. En ese sentido, si no advirtiéramos el peso que la influencia de la moral católica impuso con sus conceptos teológicos en esta mirada, nos resultaría contradictorio que partiendo la fuente principal de su informe del concepto de "insumisión natural" de los indígenas, el religioso turinés haya sido capaz de elaborar una idea alternativa, la de "indígena infiel", que los transformaba en seres básicamente redimibles, sujetos de evangelización y educación (Nicoletti, 2005).

En base a esta idea y sin abandonar el estereotipo del "salvaje", los misioneros de las distintas órdenes que evangelizaron América resignificaron esta imagen sosteniendo su 
núcleo duro e inclinando de esta manera la balanza hacia la protección, el paternalismo y su propia acción mediadora, "secularizando su rol" (Boccara, 2003, p.363) y reforzando la subalteridad aborigen. En ese estatus, el sujeto adoctrinado y bautizado pasaba a ser "indígena converso", nunca del todo equiparable al "converso", pues siempre se reforzaba en la palabra indígena la situación previa de "infidelidad" y la situación subalterna de "minoridad". Esta situación jugó un rol fundamental en el concepto de su "capacidad" para la asimilación de la nueva religión que los Salesianos decodificaron como la "educar en la fe y civilizar". Los misioneros salesianos aún reconociendo en los indígenas "un alma espiritual como nosotros dotada de inteligencia y voluntad" (Milanesio, 1980), sostenía que lograr un camino de igualdad ante la ley y la sociedad se instrumentalizaba en la misión, que se constituyeron en "espacios plurales de la normatividad (misión, escuela de indígenas, caciques embajadores, parlamentos, comercio en ferias, alianzas hispano-mapuche, etc.), que se articulan entre sí y conspiran en el sentido de la empresa de civilización" (Boccara, 1993, pp. 300-301). Este paciente trabajo educativo vigilaba y disciplinaba cuerpos, palabras y emociones. "La misión se constituye entonces como un campo de fuerzas, y la civilización del salvaje se confunde con el aprendizaje de la docilidad" (Boccara, 1993, p.289). La educación sistemática en la fe permitía que la evangelización se convirtiera en una "empresa de vigilancia que permite, supone e implica el ejercicio en un poder de censo, registro y contabilidad" (Boccara, 1993, p. 291). El aprendizaje memorístico del catecismo se realizaba "de tal manera que el que la aprendía supiera, no sólo lo que debía creer para salvarse, sino también cómo lo tenía que llevar a la práctica (Vanzini 2001, p.122 y Astete, 1886, pp. 20-21).

14 En la prédica de la doctrina, la conversión era señalada como resultado final tras la imposición del sacramento del bautismo. Mediante el bautismo las misiones imponen una nueva relación de poder que marca un orden: el registro en un acta del bautismo que une a ese individuo a la Iglesia, el nuevo nombre cristiano y los padrinos que velan por la continuidad de su fe. Para los misioneros, los indígenas eran "infieles" antes del bautismo pero eran calificados como "indígenas conversos" tras el sacramento y no simplemente como "conversos", estableciendo una diferenciación entre la feligresía.

Este proceso no estuvo exento de violencia material y simbólica. Aunque ambas formaron parte del mismo dispositivo de violencia física en sus acciones, buscaron diferenciarse discursivamente. La violencia material que llevó adelante el ejército está presente en los crueles episodios narrados detalladamente en el documento. Si bien el autor del texto perteneciente a la Congregación menciona en dos oportunidades intercambios de niños indígenas entre el ejército y la Congregación (pp. 9 y 13), no menciona ni las causas ni las consecuencias de una práctica misionera frecuente, que era la de separar a los niños y jóvenes indígenas de sus familias para llevarlos a educar y trabajar en los colegios y hospicios. Esta práctica que el misionero Beauvoir justificaba (ACS, caja 65, Memorias del P. Beauvoir) ${ }^{15}$, implicaba en la mayoría de los casos que los padres no volvieran a ver sus hijos, como fue el caso de Rosario Burgos, la madre de Ceferino Namuncurá (Pedemonte 1943 , testimonio 88 p.115 $)^{16}$. Este hecho ha sido también narrado en otro documento en el que los padres le decían al misionero que "no podría soportarlo y la madre enfermaría y quizás moriría de dolor" (BS 11,1909).

16 La violencia resignificó y condicionó las relaciones entre los actores en el entramado de la evangelización. En el caso de la violencia simbólica, su poder, como señala Boccara, se inscribe en un proceso continuo cuando es ejercida por los misioneros y discontinuo 
cuando interviene el ejército con las armas (Boccara, 2003, p. 301). Pero también esta violencia simbólica continua se advierte, por ejemplo, en las políticas educativas del Estado como ha sido la aplicación de la ley 1420 para "educar en la argentinidad". En las escuelas existió una terminante prohibición de hablar la lengua originaria e imponer el castellano y un estricto calendario de efemérides patrias.

Cuando ambos agentes actúan en un proceso de conquista, es factible que el ejercito legitime su acción apoyándose en la política misionera, como en términos generales ha sucedido en la etapa colonial, pero también es posible que los términos se inviertan y sean los misioneros los que necesiten la entrada del ejército para "civilizar", como ha sucedido en el caso que presentamos y que después genera conflictos entre ambos actores sociales por la disputa de hegemonía entre el Estado y la Iglesia para "argentinizar" y "cristianizar" el territorio. El Estado por medio de la violencia del ejército sometió a los pueblos originarios como "sujetos subalternos" con obligaciones y sin derechos y la Congregación salesiana por medio de sus programas religiosos y discursos normativos, construyeron sujetos de evangelización a través de la instalación y reiteración de ciertas prácticas misioneras, como el adoctrinamiento catequístico, la administración sacramental y la erradicación de prácticas religiosas indígenas. En este campo se cruzaron las tensiones generadas por la imposición y también por la búsqueda de consenso pero sólo como medio para alcanzar el objetivo de la "conversión", bajo un modelo cultural y religioso marcadamente eurocéntrico. Sin abandonar el estereotipo del "salvaje", los misioneros salesianos resignificaron esta imagen sosteniendo su núcleo duro e inclinando de esta manera la balanza hacia la protección, el paternalismo y su propia acción mediadora reforzando el "estatus de minoridad" y subalteridad aborigen.

Las acciones violentas y los discursos enfrentados entre Iglesia y Estado atravesaron los planes y la puesta en marcha de las misiones en la Patagonia. Don Bosco daba cuenta en su informe del propósito del Estado argentino de eliminar a los pueblos originarios mediante el avance inexorable del ejército. Allí describía una situación de violencia estatal que se posicionaba más como "un acto de recuperación que de expansión" (Briones y Delrio, 2000, p. 31). Desde este punto se observan una serie de dispositivos que enumera Salomón Tarquini para borrar la huella de los sobrevivientes tales como: la desvalorización de las prácticas culturales indígenas y la sobrevalorización de las de la inmigración europea, el énfasis en los indígenas muertos en el combate por sobre otras muertes que diezmaron la población indígena (enfermedades, hambre, frio, etc.), la identidad con el cambio de nombre en los registros censales y parroquiales, la desestructuración de sus propias redes sociales y reestructuración mediante mecanismos de confinamiento o separación y finalmente el reparto y distribución arbitraria de tierras (Salomón Tarquini, 2010, pp. 51-52).

19 Para el fundador de los Salesianos, las consecuencias de esta violencia perpetrada significaron la devastación y la expulsión de sus tierras, "donde tienen derecho a estar" (Ceria, t. III, Lettera 1676) ${ }^{17}$. En su informe Don Bosco relata que quienes exterminaban y expulsaban a los indígenas eran los "argentinos" y los "chilenos" (Bosco y Barberis, [1876] 1988, p. 158; Ceria, t. III, Lettera 1676), respondiendo a los "crueles" malones indígenas a los que calificaba como una respuesta exasperada. Su conclusión era que si los "salvajes" no conocían la fe respondían a la violencia con más violencia, y entonces "sólo el misionero con su conducta de paz puede poco a poco deponer el odio contra lo europeo y con la religión introducir la civilización" (Bosco y Barberis, [1876] 1988, pp.161 y 180). Los términos con los que Don Bosco calificaba estos hechos nos revelan también su plan de 
“civilización y evangelización" sobre los pueblos originarios y sus territorios. Para Don Bosco la estrategia para convencer a los lonkos de sus buenas intenciones y de las ventajas que la "religión y la civilización" introduciría en estos pueblos, consistía en una negociación cautelosa en la que sus misioneros se posicionaban como intermediarios ante el gobierno argentino "para obtener favores, pero no para someterlos. El resto lo hará la providencia" (Bosco y Barberis, [1876] 1988, p.164).

Estas fuentes salesianas han sido interpretadas por historiadores de la Congregación como Raúl Entraigas, ${ }^{18}$ Pascual Paesa ${ }^{19}$ y Cayetano Bruno, ${ }^{20}$ que mencionan y contextualizan la conquista en sus historias de la Congregación (Entraigas, 1972, t. III, pp. 25-11; Bruno, 1981, t. I, pp. 254-269). En el año 1979, centenario de la conquista, publicaron un libro conmemorativo titulado "La expedición al desierto y los Salesianos", en el que Entraigas, Bruno, Belza ${ }^{21}$ y Paesa, escribieron cada uno un capitulo. El texto tiene en términos generales una marcada tendencia militarista (Belza, Entraigas, Bruno y Paesa, 1979). Los trabajos que se centran específicamente en el tema de las campañas militares, son el de Juan Belza y Raúl Entraigas, cuyo tratamiento sobre la situación indígena y la figura de Roca difiere en algunas cuestiones de los trabajos de Cayetano Bruno y Pascual Paesa. Los dos primeros básicamente sostienen la "necesidad" de la conquista ante el malón y la hostilidad indígena silenciando la violencia y exaltando la tarea civilizadora del ejército. Paesa sigue el concepto de la campaña de conquista como " un desfile, un avance frontal sin dificultades" entre los "salvajes" (Paesa, 1979, p.179), pero al citar como fuente principal, transcripciones textuales de los Boletines salesianos, las mismas descripciones de la situación de los indígenas y la violencia del ejército, marcan la contradicción con algunas afirmaciones y con los trabajos de Belza y Entraigas. Entraigas justifica el ingreso de los salesianos con el ejército "la cruz que es una espada que salva, y la espada que es una cruz que castiga completarán la conquista de una docena y media de leguas para la civilización" (Entraigas, 1979, p.45). Mientras que para Paesa el civilizado es el peor enemigo del indígena, pero no porque lo aniquila sino porque es causa de antitestimonio evangélico (Paesa, 1979, p.182). El trabajo de Entraigas sigue básicamente el diario de Espinosa y algunos relatos sesgados de Costamagna de todo el recorrido desde Carhué al Colorado. Es evidente que de los relatos de Costamagna, Entraigas y Paesa realizan selecciones diferentes. Mientras Paesa se centra en la acción misionera, a Entraigas le interesa fundamentalmente destacar la tarea "civilizadora" de los salesianos, del ejército y del Estado. En síntesis, el ingreso de los Salesianos con Julio Roca y la violencia que se desató en todo el territorio resultó un tema controvertido dentro de la Congregación cuya discusión se dirimió entre el cuestionamiento de la campaña militar y la intervención de una congregación religiosa en este hecho (Nicoletti, 2007). Los Salesianos comprendieron que la violencia material los alejaba de su objetivo evangelizador y resultaba un obstáculo para la imposición de la nueva fe (Bollettino Salesiano, 5, 1879, pp. 4 y 5). De esta manera se terminaba justificando su intervención en las campañas de Roca:

El Gobierno entonces se mitigó y pidió consejo y ya presentemente se está instruyendo y bautizando a estos infelices relegados en las islas. A causa de la varicela, centenares se van muriendo, mientras los otros sin número determinado todavía están languideciendo en la soledad del desierto. Para tal fin, y para proveer a estos desgraciados, y para comunicarse con los remanentes de las tribus, nuestros misioneros salesianos en estos días están en viaje por segunda vez y esta vez no por mar, sino por tierra. (...). Son acompañados por el Doctor Antonio Espinosa, secretario del Arzobispo y por el mismo Ministro de Guerra, convertido ahora Ministro de la paz (Bollettino Salesiano, 5, 1879, p.5). 
La idea naturalizada de la "conquista del desierto" (Navarro Floria, 2005) en torno a la catolicidad del territorio, fue tomando la forma contradictoria de la "gesta heroica" mientras que, la violencia perpetrada, se colocó en el discurso salesiano, si lo leemos atentamente, antes de la expedición de Roca: si Roca es "ministro de paz", los Salesianos acompañan a una "misión de paz" y no de guerra. Y en ese contexto, la religión lograba "civilizar" a quienes estaban condenados a la extinción "por su propia inadecuación", o a quienes por su "naturaleza salvaje" se rebelaban. La gesta religiosa lograba de este modo minimizar "el acontecer de acciones incruentas" (Bollettino Salesiano, 5, 1879, p.5), pero paradójicamente mientras categorizaba su acción como "conquistadora", condenaba la violencia del ejército marcando las diferencias:

No entendemos este título glorioso de alabar a los que con las armas en la mano penetraron el año pasado en el desierto de los Pampas y lo conquistaron. Este título ilustre creemos que conviene con mayor verdad a los Misioneros salesianos" (Bollettino Salesiano, 5, 1879, p.5).

En este contexto de violencia material, según el testimonio los verdaderos héroes son los salesianos con su "conquista pacífica de las almas", ${ }^{22}$ pero resultaba fundamental para la Congregación diferenciarse claramente de la violencia estatal. En ese sentido, la secularización emprendida por el Estado decimonónico y sus acciones anticlericales sirvieron para que los misioneros se posicionaran también como víctimas de las autoridades y de las acciones del ejército. Las leyes de educación laica (1420) y de matrimonio civil (2393) mermaron considerablemente el poder de la Iglesia. En un ámbito en construcción como la Patagonia pos conquista, donde el aparato del Estado se imponía lenta y tardíamente, la Congregación salesiana disputó los espacios educativos con la confección de un subsistema católico y privado (Nicoletti y Navarro Floria, 2004 y Nicoletti,2007); los espacios civiles, quejándose e interviniendo en los juzgados para las celebraciones del matrimonio (Nicoletti, 2012); los espacios sociales con hospitales, oratorios festivos, bandas de música, orfanatos y los espacios públicos en celebraciones, homenajes, agasajos, procesiones, capellanías y festividades cívicas y católicas (Fresia, 2013). Esta disputa sobre qué agencia debía civilizar y cómo debía hacerlo es el objeto del documento que describimos a continuación.

\section{Breve relación de las misiones de la Patagonia hecha en 29 setiembre de 1887. El militarismo patagónico. El General Villegas por el sac. Antonio Ricardi, secretario de Monseñor Cagliero}

\subsection{Presentación}

La fuente que analizamos en este trabajo ha tenido el siguiente derrotero. Una copia del documento, cuyo manuscrito original se encontraba en el Archivo Salesiano Central de Buenos Aires, ingresó fotocopiado en el año 2010 al Archivo Histórico de las Misiones Salesianas de la Patagonia (Bahía Blanca), según consta en un documento de registro y transcripción (Archivo Salesiano Patagónico, Breve relación de las Misiones de la Patagonia, 2013). El documento tiene un sello de pertenencia de la Inspectoría Salesiana San Francisco Javier, jurisdicción interna de la Congregación Salesiana, a la que pertenecía el Archivo Histórico de las Misiones Salesianas de la Patagonia Norte o 
también denominado actualmente como Archivo Salesiano Patagónico, en la ciudad de Bahía Blanca.

La clasificación de los archivos históricos salesianos en la Argentina, siguió la línea de organización interna de las inspectorías anteriores a la reforma inspectorial del año 2010. ${ }^{23}$ De este modo, para la Patagonia continental, exceptuando la provincia de Santa Cruz, anteriormente dependiente de la inspectoría San Francisco Javier, la documentación se encuentra en el Archivo histórico de las misiones salesianas de la Patagonia Norte (Archivo Salesiano Patagónico) en la ciudad de Bahía Blanca, que comenzó en época del rector mayor Don Ziggioti en 1956, año en el que visitó la Argentina. Para el caso de la Patagonia sur, o sea para las jurisdicciones correspondientes a la antigua Prefectura apostólica, perteneciente por entonces a la inspectoría de San Francisco de Sales; su reservorio se concentra en el Archivo Central Salesiano en la ciudad de Buenos Aires. ${ }^{24}$

El salesiano Valentín Rebok, fallecido en el año 2012, fue el encargado del Archivo Inspectorial desde 1992 y trabajo también sistemáticamente en el Archivo histórico. El P. Rebok le proporcionó a Iván Ariel Fresia, también salesiano, una copia de este documento. Es posible también consultar esta copia mediante una visita al Archivo Salesiano Patagónico donde el documento ha sido catalogado y transcripto. Utilizamos también en este trabajo la transcripción del documento efectuada por el personal del Archivo.

El documento corresponde a un cuaderno de notas del sacerdote Antonio Ricardi ${ }^{25}$, que se desempeñó desde su llegada a América en 1885 como secretario del Obispo Juan Cagliero, Vicario apostólico de la Patagonia. Debemos tener en cuenta que el Obispo Cagliero, como Vicario apostólico y superior de las Misiones salesianas en la Patagonia, realizó desde 1880 giras misioneras recorriendo el territorio. Ricardi describe hechos anteriores a su llegada acaecidos entre 1881 y 1886, que seguramente ha leído en las cartas y memorias publicadas en el Bollettino Salesiano ${ }^{26}$ o bien como secretario ha recogido como testimonio directo.

Es evidente por las tachaduras y agregados de palabras aclaratorias, que el documento fue re leído y retocado para mayor claridad del lector y del relato ajustado de los sucesos. Varios de los episodios pudieron ser identificados pues fueron relatados por Domingo Milanesio y José Beauvoir en sus cartas y memorias publicadas en los Bollettini Salesiani en sus escritos, pero otros episodios en los que José Fagnano estuvo involucrado no aparecen en los relatos de sus expediciones junto a Villegas entre 1881 y 1883. Justamente el manuscrito de Antonio Ricardi termina diciendo que: "Todo esto debería recordar y mucho mas, pero mejor que yo podrá desempeñar este cargo el director de las misiones $\mathrm{D}$. Fagnano que es perfecto conocedor de todo lo acaecido en estas dos poblaciones del Río Negro" (p.17).

Las notas que vierte Ricardi en este documento están matizadas entre juicios de valor y hechos concretos que selecciona para ejemplificar sus ideas. El tema central gira en torno a las relaciones entre las autoridades y oficiales del ejército con los misioneros salesianos. La actitud "militarista" que describe Ricardi es la que impide, según su concepción, la conversión al catolicismo de los pueblos originarios y la "civilización" entendida como el desarrollo de la Obra educativa y de conversión al catolicismo o sea la implementación de "Iglesias y colegios católicos" (p.3), "especialmente para los huérfanos que si no son educados a tiempo toman el mal camino especialmente en este lugar donde la buena costumbre no es lamentablemente la mayor virtud" (Bollettino Salesiano,10,1881, p. 8). 
Los términos "barbarie" y "civilización" se resignifican en este documento en función de la tarea evangelizadora contra la que, según la Congregación, se opone de parte del ejército: el "militarismo". La "barbarie", según los Salesianos, nace de las acciones de conquista que desatan una cruel violencia impidiendo que se instale la "civilización" identificada con la "moral católica" a la que Ricardi llama la "verdadera civilización" (p.7). Esta idea de "barbarie" la había explicitado en una carta Santiago Costamagna a Don Bosco en plenas campañas militares:

No soy el más indicado para apreciar ciertos hechos y ciertos derechos que, hombres que se dicen civilizados se arrogan sobre otros que se apellidan bárbaros (...) algunos militares graduados, de corazón podrido, corrompidos y corruptores que no saben abrir la boca sin decir bestialidades o eructar inmundicias se compadecen de los primeros [soldados] y los llaman infelices. (Archivo Central Salesiano, Caja 203, 1879)

Si bien ambos salesianos coinciden, Costamagna intenta morigerar la denuncia añadiendo que: "No quiero decir con esto que todos los graduados fuesen de la misma pasta, absolutamente" (Archivo Central Salesiano, caja 203, 1879), antes bien, para el salesiano Ricardi este documento identifica al ejército como "la rémora" de este binomio “civilización y barbarie" (p.3).

31 La idea de "civilización y progreso", la explicitan los misioneros en distintas cartas y memorias y se identifica fundamentalmente con la Iglesia católica y no con Estado nacional decimonónico que promueve "leyes laicas" y busca frenar la injerencia de esta institución. Para los Salesianos "civilizar" era proveer a los habitantes originarios de aquello que, a su parecer, carecen: casa, trabajo, vestido, pan, conocimiento y "creer en nuestro buen Dios" (Bollettino Salesiano 9, 1881, p. 9). Algunos salesianos como Chiara y Milanesio, formulan un plan civilizatorio con la formación de "un colonia donde abrir escuela y enseñar los quehaceres necesarios para la vida civilizada especialmente la agricultura la más indispensable para la vida cotidiana y en tanto instruirlos en la religión cristiana para llevarlos al cielo" (Bollettino Salesiano 9 1881, p. 10; 6 1881, p. 5; 7, 1884, p. 3; 7, 1884, p. 94). La asociación entre educación en la fe católica y la "civilización" era para los Salesianos la base de su proyecto: "del miserable estado en el que han quedado se los puede sacar la Religión cristiana que solo da a los creyentes la verdadera libertad junto con la civilización" (Bollettino Salesiano 7, 1883, p. 112).

Si bien el documento habla en general de "misioneros" y "misioneras", en los hechos se identifican a algunos de sus protagonistas: Milanesio, Cagliero, Fagnano y Beauvoir. Para el caso de los militares, el autor encarna su idea de "militarismo" en el General Villegas. Esta identificación surge claramente del subtitulo del documento y de los hechos, que desde la página 9 hasta el final tienen a Villegas como protagonista.

Las conceptualizaciones han sido construidas desde su pertenencia a la Congregación y en defensa de la acción misionera señalando los hechos concretos que la obstaculizaron, a los que Ricardi decodifica como "militaristas". Estos hechos, relatados con hondo dramatismo, se refieren a la violencia contra los pueblos originarios y a la actitud "anticlerical" e "impía" de los oficiales del ejército. Las crueles acciones del ejército, caracterizado como "tirano vencedor", ya habían sido calificadas como "ejército conquistador" (Bollettino Salesiano 10, 1881, p.8). Estas acciones son relatadas desde el concepto de "conquista" del territorio hacia los "indios sometidos" (p. 6) y "reducidos" (p. 14), con calificativos concretos y directos, que ya encontramos en la carta de Costamagna de 1879 y en los Bollettini Salesiani citados: "prisioneros de guerra", 
"exterminio", "masacre" y la "violación de los derechos de los vínculos de familia" (Archivo Central Salesiano, caja 203.1.1879; Bollettino Salesiano 5, 1883, p.8). Ricardi ilustra esta denuncia relatando los asesinatos (p. 5), la separación de familias (p. 9), el trabajo esclavo (pp. 8, 14 y 15) y los "barbaros maltratos" (p. 6). Sucesos de índole tan diversa como la violencia y la crueldad hacia individuos indefensos se mezclan en el relato con las burlas "anticlericales" en un mismo tono de denuncia.

Para el análisis del documento, presentaremos una descripción de las distintas partes en el que se puede organizar, aludiendo a las fojas que comprenden y los títulos o subtítulos que las integran.

\subsection{Estructura}

El autor sitúa temporalmente los hechos relatados por el documento: la acción misionera salesiana "desde ocho años" (1879-1887). Los resultados de esta acción han sido el "indiferentismo", la "impiedad" y la "ingratitud" de los "dos pueblos incipientes de la región patagónica". Ambos pueblos, los originarios y los extranjeros, pertenecen a una franja etaria concreta: los adultos, "la generación vieja" de los que "no se recogieron hasta ahora más que las punzantes espinas del mas podrido indiferentismo", "por lo terca y obstinada que es en sus máximas". En cambio, señala el autor, es la "niñez y la adolescencia" el "objeto de nuestras esperanzas". Los jóvenes y los niños, cuya asistencia y educación forma parte del carisma de la Congregación salesiana a quienes el salesiano identifica como los "cimientos, si bien labrados, de un pueblo cristiano". Domingo Milanesio ya había planteado en medio de sus campañas misioneras, que: "para esto no nos falta la buena voluntad donde sino podemos educar al Indio con la autoridad y apoyo del gobierno, los educaremos con aquellos medios que el Señor no permitirá que nos falten, supliendo con caridad y paciencia el prestigio de la autoridad y de la fuerza" (Bollettino Salesiano 7, 1883, p.112). La educación enfocada en los niños y jóvenes responde al carisma educativo salesiano como señala el salesiano Bernardo Vacchina, porque ellos muestran "un carácter más dócil y se obtendrían más abundantes frutos si viviesen entre verdaderos cristianos, como nos lo demuestran los resultados obtenidos con los indios de nuestras casas" (Boletín Salesiano 7, 1909). Esta focalización también responde a su percepción del aprendizaje de la doctrina en el indígena adulto al que califican de "dócil pero con poca retención por defecto del ejercicio de memoria" (Bollettino Salesiano 7, 1881, p.11). Como decía el salesiano Pedro Marabini, "un indio adulto es simplemente un niño grande" (Marabini,1906, p. 56). En la práctica misionera, Milanesio realiza un extenso y pormenorizado relato de cómo impartir la enseñanza de la doctrina en adultos y en niños (Bollettino Salesiano 7, 1884, p. 93). Si bien, esta no es la fundamentación del trato de minoridad del indígena adulto sometido, que en otro documento sí justifica (ACS, caja Patagonia 203.3 (5), s/f.), seguramente colaboró como reaseguro de este estatus explicitado en la Constitución de 1853 por el Estado.

Fs. 2-4

El autor dedica esta página a definir el concepto de "militarismo", en función de las acciones negativa que ocasiona: "impiedad" y "desmoralización". Inmediatamente construye este concepto en el territorio de misión de la Congregación, la Patagonia, posicionándolo como el principal "obstáculo de la Religión", "centro de la corrupción y de la inmoralidad"; parangonándolo con un dique a la "prédica y al celo" de lo que llama los 
apóstoles de la verdad o sea los misioneros salesianos. A estos misioneros se oponen los agentes del "militarismo", que para Ricardi son los militares y los empleados, ${ }^{27}$ especificando después la caracterización del militar argentino patagónico ${ }^{28}$ como " naturalmente orgulloso, simulador entusiasta, falto de buen carácter, sectario y feroz". Las situaciones de conducta inmoral, poco propicia para la evangelización de los indígenas, aparecen en los Boletines Salesianos, bajo distintos calificativos (Bollettino Salesiano 7 1881, p. 11). Esta caracterización centrada en el "antitestimonio cristiano" la había formulado Domingo Milanesio en una carta enviada a Don Bosco en 1884 donde menciona a los soldados como "la cruz de los misioneros que con su conducta poco cristiana ponen un grave obstáculo a la conversión de los salvajes" (Bollettino Salesiano 7 1884, p.3).

La referencia al territorio lleva inmediatamente a la caracterización más contundente y original de este documento: la Patagonia es un territorio "conquistado con la barbarie". Conquista nos habla de un territorio tomado por la fuerza, a la que este salesiano le agrega la metodología contra sus habitantes originarios: "el despotismo sangriento inhumanamente ejercitado contra los indígenas sometidos", mediante "las acciones más crueles e infames". Como afirma Navarro Floria,

(...) el proceso de distribución de la propiedad territorial en la Patagonia Norte después de su conquista por la Argentina, fue desde el más alto nivel del Estado nacional hacia los actores concretos e individuales. Los Territorios Nacionales fueron definidos como colonias internas del Estado, y sus habitantes privados de todo derecho a la tierra, a la cultura y a sus propias pautas de vida (Navarro Floria, 2009, p. 32).

Para Ricardi solo los sacerdotes pertenecientes a la Congregación salesiana son aquellos que, sin complacencia, denuncian los ultrajes a los indígenas y a la moral católica por parte de los militares. Esta idea del "clero relajado" que aparece en el documento y que los Salesianos identificaban con algunos miembros del clero secular, la vuelve a formular Domenico Milanesio en 1904 en su escrito "Consigli e proposte agli emigranti italiani alle regioni patagoniche dell'America del Sud" (Consejos y propuestas a los inmigrantes italianos a las regiones paagónicas de la América del Sur), donde propone un proyecto de colonias mixtas acompañado por un clero de migrantes italianos, como los Salesianos, en oposición a un clero poco preparado y "apegado al campanario" (Nicoletti y Navarro Floria 2004, p. 360)

Fs. 5-9

A partir de la página 5 del documento, Ricardi ilustra las actitudes "militaristas" y "anticlericales" junto con acciones violentas llenas de crueldad. En reproche a su "vida escandalosa" el Capitán Peralta Martínez desafía al P. Beauvoir (Bevoir) a duelo en 1882 (p. 5). Ese mismo año, sitúa el autor un cruel suceso en la primera expedición al Nahuel Huapi perpetrado por un teniente "tan sólo por el gusto brutal de ver" el degüello de un "indio sometido" que iba caminando "donde quería el tirano vencedor", frente al P. José Fagnano. Según Ricardi, Fagnano siente "dolor y espanto" y no arremete contra el teniente por "la ley de la caridad" y "por el peligro en que se hallaba en medio de fascinerosos" (sic) (p. 6).

Las páginas 7 y 8 se centran en situaciones que pueden calificarse como "anticlericales". El P. Milanesio que en 1884 fue "desterrado" de la Patagonia siendo capellán (p.7) y el P. Remotti (Rernotti) que en 1886 (p. 7) fue tomado prisionero por el mismo motivo, como relata un biógrafo de la Congregación: 
(...) el año 1885, luego de superar la oposición del General Lorenzo Vintter, gobernador del Territorio de Río Negro, el padre Remotti ocupó el cargo de párroco de Viedma. Tuvo que sufrir mil arbitrariedades de parte del gobernador y sus sumisos secuaces (Dumrauf, 1998, t. II, p. 40). episodios con diferentes protagonistas, para mostrar hasta donde pueden llegar las acciones del "militarismo". En la primera secuencia, el General Vintter intentó a punta de pistola quitar de su puesto al Juez de Paz y en la segunda, un grupo de "militares y empleados", gritan por la noche en la puerta de la Iglesia de Carmen de Patagones " $¡ A b a j o$ el cura Fagnano!, mientras que se enviaba un telegrama a Buenos Aires noticiando que frailes y monjas por sus desórdenes habían sido desterrados para siempre de la Patagonia (p. 7). El relato muestra que estos hechos acaecidos en la Patagonia Norte se han dado a conocer públicamente a través de los diarios dedicados a "denigrar y aniquilar la fama de los misioneros salesianos" (p. 8) con toda clase de calificativos denigrantes de los que ninguno está exento, ni "el señor obispo". Este documento es uno de los tantos que los Salesianos produjeron para responder acusaciones del Estado. El periódico Flores del Campo (1903-1947) que condenaba a los "males de la modernidad y al socialismo", el escrito de Pedro Marabini "Los Salesianos y las riquezas del Sud" (1906) respondiéndole al Vocal del Consejo de Educación José Zubiaur sobre la educación católica o los escritos de Milanesio editados e inéditos y los de su biógrafo Garófoli (1928), contra el poder estatal y militar; son algunos de los ejemplos.

Ricardi defiende a los misioneros acusando a los militares y autoridades del territorio de corrupción por quedarse con el sueldo de capellán de la Gobernación de Río Negro, cometer fraude con el alquiler de la casa parroquial de Patagones "convertida en hospital para los soldados enfermos" y extraer por la fuerza la arena del terreno destinado a la Iglesia de Viedma (p. 8) para impedir la construcción del Templo. Los hechos narrados para Ricardi son aun más graves si se tiene en cuenta que la actitud de los Salesianos e Hijas de María Auxiliadora ha sido respetuosa e incluso, de acuerdo a una serie de sucesos narrados, también complaciente, tal como relata en la página 9. Por ello, le resulta inexplicable al salesiano que Vinter que "parecía amigo de Don Fagnano" y que le había dado "cinco indígenas a quienes se instruían en la religión y en las artes en el colegio de San José", tras los sucesos con Don Milanesio, "(...) envía a un capitan para extraer á los cinco niños del colegio los cuales salieron llenos de dolor y fueron distribuidos en el mismo dia á varios empleados que les hacían llevar una vida de verdadera esclavitud". La sucesión de relatos vejatorios a los derechos de las personas, en este caso los indígenas, se mezclan en estas páginas con otros que atentan contra la investidura religiosa.

A partir de la página 9 Ricardi se centra en figura de Villegas, nombre que agrega con posterioridad en esa frase del manuscrito, pero al que hace alusión constante mencionando los hechos que se sucedieron en las dos expediciones al lago Nahuel Huapi. Ricardi menciona con precisión los años de las expediciones, la primera en 1881 y la segunda en 1883 y a los coprotagonistas de los sucesos que posteriormente relata: los salesianos Fagnano y Beauvoir. Seguramente la fuente de estos hechos hayan sido las cartas publicadas en los Bollettini Salesiani. En la primera campaña, relata Fagnano, fueron apresados un centenar de indígenas entre hombres, mujeres y niños, que no había logrado huir a Chile y que él acompañaba con el ejército para catequizar y bautizar (Bollettino Salesiano 10, 1881, p. 9). 

piensa que en ese momento "Villegas à pedido del sacerdote prometía de dar al colegio de San José unos diez indios y otras tantas indias para el colegio de las hermanas de caridad para educar en la religión y en las artes" (p. 13), como también prometió ceder la casa del fuerte, sin cumplir ninguna de las dos cosas. Las relaciones entre Villegas y los Salesianos, especialmente Fagnano, no parecían en un principio, según relata Ricardi, de confrontación. En algunos Bollettini Salesiani, Villegas busca la colaboración de los Salesianos, “(...) para que preparen misioneros porque están en viaje unos 700 indios para ser sometidos" (BS 2, 1883, p. 7). Pero, tras este prolongado relato de cuatro fojas, Ricardi vuelve a un tema central que había mencionado en la página 10: los "trescientos indios de ambos sexos y de todas edades medio desnudos" que Villegas había dejado en la plaza.

En la página 14 Ricardi retoma este relato completando la descripción de los indígenas "maniatados y custodiados por los soldados en armas" (p. 14). Fueron, según el salesiano, conducidos del "muelle ${ }^{29}$ al fuerte y colocados entre los cimientos de la nueva iglesia". Allí permanecieron a la intemperie más de un mes, como dice literalmente Ricardi, en situación de "esclavitud". Ante esta situación Fagnano solicita permiso para bautizarlos y vestirlos. Pasa después el secretario de Cagliero a relatar una "trágica escena" (p. 15) parangonándola con la escena bíblica "del degüello de los inocentes". La escena se desarrolla en dos secuencias, primero una acción sobre el grupo que es calificada de "esclavización" y después la focalización en una madre que arroja su bebé a los soldados y dice una frase que le incorpora a la escena mayor dramatismo:

Los soldados por órden del general Villegas entran en los cimientos de la iglesia, se arremeten contra las cautivas indijenas ${ }^{30} \mathrm{y}$ les arrancan à los hijos con violencia, los separan y distribuyen à los particulares que los piden y à los oficiales para que los esclavizen. Fué entonces que hubo una madre que ya no pudiendo resistir el dolor arrojó de sí à una criatura de pecho diciendo llena de rabia: "tomad también esta, asesinos y saciaos de la sangre à vuestro placer". 

fuente (Entraigas, Raúl, 1945, p. 162). La escena pasa después a la descripción de la sensación de impotencia de Fagnano que tampoco logra obtener los indígenas para el colegio a pesar de los "homenajes", "respeto y acatamiento" e incluso la celebración de su funeral (p. 16). Este relato brutal y dramático termina nuevamente con episodios de burla anticlerical a Fagnano, a las Hermanas de María Auxiliador donde en los bailes de carnaval de Viedma se disfrazaban los soldados de "obispo, cura, frayles y monjas" (p. 17). Esto parece haber sucedido en 1887 pues Ricardi menciona que "el año venidero 1888 se harà peor difrazándose también de papa" (p. 17).

El documento finaliza cuando su autor da cuenta del testimonio indirecto de los hechos relatados, diciendo que sería mejor aún un documento escrito por uno de sus protagonistas, José Fagnano "perfecto conocedor de todo lo acaecido en estas dos poblaciones del Río Negro" (p. 17). Recién en 1945 el historiador Raúl Entraigas recoge testimonios sobre Fagnano y sus publicaciones para realizar su biografía. Para Ricardi esta ha sido una "breve historia" del "militarismo", la "ingratitud" y la "persecución" que "tuvieron que sufrir los misioneros salesianos" (p. 17). Según este salesiano, si los misioneros continuaron con esta tarea fue porque los "guia, protege y defiende" "la divina providencia", que los "lleva seguros al puerto de la salud y de la gloria" (p. 18).

\section{Conclusiones}

El documento "Breve relación de las misiones de la Patagonia" (1887) escrito por el secretario del Obispo Cagliero, Antonio Ricardi, da cuenta de hechos acaecidos entre 1879 y 1883. Estos acontecimientos tuvieron como actores sociales a los misioneros y misioneras de la Congregación salesiana, los pueblos originarios y los militares que conquistaron la Patagonia. El texto se centra especialmente en la Patagonia Norte y particularmente en las campañas al Nahuel Huapi llevadas a cabo por el General Villegas. Prácticamente la mitad del documento está dedicado al comportamiento del General Villegas, cuyo nombre integra el subtitulo del escrito y que para el autor encarna aquello que denomina "militarismo".

Si bien Ricardi no estuvo presente en los acontecimientos relatados pues llega a la Patagonia pocos años después, en 1885 , tuvo contacto con quienes fueron protagonistas o testigos directos. De todos modos, hemos comprobado que algunos de los hechos narrados se encuentran reescritos casi textualmente de los Bollettini Salesiani. Por otro lado, sabemos que este documento, perteneciente a su cuaderno de notas, ha sido revisado con reescrituras parciales de acuerdo a las tachaduras o palabras incorporadas sobrescritas que se advierten en el original.

El documento es un relato que mezcla conceptos y juicios ilustrados con acontecimientos.

Estos conceptos son fruto de su pertenencia a la Congregación salesiana. De allí que para el salesiano Ricardi haya sido el militarismo el principal obstáculo del éxito de las misiones de la Congregación. Este salesiano conceptualiza el "militarismo" en torno a las acciones inmorales, impías y anticlericales de los miembros del ejército contra los Salesianos y las Hijas de María Auxiliadora, pero también incluye en el relato los hechos violentos de conquista contra los pueblos originarios. Dentro de la misma sucesión de acontecimientos se describen asesinatos y esclavizaciones tanto como burlas y sacrilegios 
en un mismo tono. Términos de uso decimonónico como "barbarie" y "civilización" son resignificados en función de la labor evangelizadora de la Congregación y del contexto de tensión entre la Iglesia y el Estado. Desde esta perspectiva son los militares los conquistadores bárbaros de la Patagonia y es la Congregación salesiana en representación de la Iglesia católica, la que lleva a un territorio en construcción a la "verdadera civilización". Su implementación tanto en el campo educativo con escuelas católicas, misionero con parroquias y misiones itinerantes, como social con hospitales y colonias agrícolas, se ve impedido, según Ricardi, por la acción violenta del ejército y la impiedad y anticlericalismo de sus miembros, especialmente del General Villegas.

La acción misionera se llevó adelante bajo los conceptos de "educar en la fe y civilizar" mediante espacios y acciones normativas que transformaron a los indígenas en "indígenas conversos" y no simplemente en "conversos", estableciendo una diferenciación entre la feligresía católica. Es decir "salvajes" pero "redimidos", iguales a todos los hombres porque son creación de Dios y por la incorporación mediante el bautismo como hijos de la Iglesia, estableciendo una nueva relación de poder que marca un orden por el registro del individuo en un acta con un nuevo nombre cristiano, con padrinos blancos que velan por la continuidad de su fe. Este procedimiento junto con los registros censales de los indígenas como argentinos nativos, se suma "a una estereotipación que sobrealimentó la importancia efectiva del aporte poblacional obtenido por vía inmigratoria, contribuyó a enmascarar la significación de la población de origen indígena, invisibilizando a sus miembros" (Salomón Tarquini, 2010, p. 52).

En definitiva, se esperaba que el sujeto evangelizado abandonara ciertas costumbres que los misioneros consideraban contrarias a la fe (la poligamia, la embriaguez y las rogativas), aceptaran la doctrina y se bautizaran. A estas estrategias "deculturadoras", se le agregaron otras "“ccomunalizadoras", en la medida en que colaboraron a generar la adhesión de estos indígenas a una identificación con la "nación argentina", a través de la asociación de ambientes festivos-administración de sacramentos-fiestas patrias en varios casos" (Salomón Tarquini, 2005, pp. 14-15). La diferenciación también opera ante la necesidad de "civilización", protección y educación en la Iglesia que es instrumentalizada políticamente para marginar o incorporar en términos de tutelaje a los pueblos originarios (Delrio, 2005, p. 150). En el recorrido por la legislación y la construcción de la “aboriginalidad" que realizan Briones (1998), Delrio $(2002,2005)$ y Lenton (2005), se observan políticas selectivas y heterogéneas que reafirma el proyecto "homogeneizador" y la invisibilización indígena. Otros trabajos siguen considerando asimilacionistas proyectos claramente segregacionistas sin diferenciar las propuestas evolucionistas de las reformistas (Mases, 2002, pp. 151 y 153).

Este proceso tuvo lugar en medio de acciones de violencia material y simbólica, en las que los actores sociales buscaron diferenciarse. La violencia material que llevó adelante el ejército, se observa en hechos concretos en el documento y sus acciones y sus consecuencias resignificaron las relaciones entre los actores sociales del territorio patagónico que disputaron hegemonía y construyeron subalteridad desde sus roles. La violencia simbólica no es mencionada, pero ha sido ejercida por el Estado, por ejemplo, con la aplicación de las llamadas leyes laicas en los Territorios Nacionales. En el contexto de violencia la Congregación evangelizó y educó a los pueblos originarios, considerados como "infieles", es decir desconocedores de la fe católica por ignorancia y no por falta de inteligencia. Sin embargo no abandonaron la categorización de "salvajes" y "bárbaros", que refuerzan el estatus de minoridad acuñado por el Estado tras la conquista y permiten 
el paternalismo y la acción mediadora de los misioneros. La violencia simbólica que surge a partir de la imposición de la nueva fe y de la educación occidental y cristiana, también fue acompañada de violencia material mediante prácticas concretas, relacionadas con el desmembramiento familias (por ejemplo: la educación y el trabajo de niños y jóvenes en internados y obligatoriedad del matrimonio monogámico). Este documento se suma a otros tantos documentos de denuncia de violencia hacia los pueblos originarios que permiten adentrándonos en el análisis histórico, estudiar las tensiones políticas y la disputa de la Iglesia con Estado por la "civilización” de los pueblos originarios a través de la imposición de la religión católica.

\section{Fuentes. ARChIVo SALESIANO PATAgÓNICO. BREVE RELACIÓN DE LAS MISIONES DE LA PATAgONIA. HECHA EN 29 SETIEMBRE DE 1887. SAC. ANTONIO RICARDI. SECRETARIO DE MONS. CAgLIERO} el tiempo; son / los cimientos, si bien labrados, de un pueblo cristia / no_Pero lo que hace más desgraciado à las dos pobla / ciones del Río Negro Patagones y Viedma es el Mi / litarismo. vórtices funes / tos: ha sido el torrente formidable de impiedad / que inundándolo todo, todo lo arrastra en su / pos y es la peste aun que todo lo inficciona, / lo desmoraliza, lo 
corrompe. ¿Qué es pues él / militarismo en estas comarcas? Es el obstáculo de / la Religion, el centro de la corrupción y de la in / moralidad, es la secta destructora de todo bien, / es la rémora de la civilización y del progreso. Talvez / el pueblo, si bien corrompido, por si mismo se / doblegaría dócil a la predicación y celo incesante / de los apóstoles de la verdad, mas un dique lo / opone tremendo el orgulloso y descreído mili / tarismo (de la Patagonia) ${ }^{32}$ y cuando hablo de militares (...) ${ }^{33}$ hablar así mismo de los empleados

Página 3:

(argentinos y extranjeros) ${ }^{34}$ que en eso de irreligión no la / ceden al oficialismo militar, pues que, siendo todos / siervos de una misma dueña, la impiedad ${ }^{35}$, no conocen derechos / y atropellan (todas) ${ }^{36}$ las leyes de la justicia y del deber. jHe ahí / la fuente de donde emana en este territorio todo de / sorden! He ahí de donde se produce la causa del / desprecio de la religión, la lucha costante contra / los misioneros de la Iglesia Católica! El mi / litar argentino (patagónico) ${ }^{37}$ es naturalmente orgulloso, / simulador entusiasta, falto de buen carácter, / sectario y feroz que siempre ha sido el obstáculo / de que se propagara la Religión del crucificado / en estos países conquistados con la barbarie y / el despotismo sangriento inhumanamente / ejercitado contra los indígenas sometidos: él / desdeña, sufre y no tolera que se restablezca la / moralidad en el seno de las familias y delos in / dividuos y para impedirlo no titubea en deshon / rarse con las acciones más crueles e infamantes /

Los militares en esta región en lugar de iglesias / y de colegios católicos quisieran salones de bailes, / teatros y concurrencias públicas: quisieran iglesias /

Página 4:

de protestandes [sic] y van mendigando un cléro relajado / que no les molesten ni conviertan y sólo aprueben / su conducta con su conducta. Y de esto es prueba / el que tanto ensalzen el nombre de ciertos sacerdotes / que han visitado estas orillas y les han obsequiado / constantemente con visitas, banquetes y concesiones / demasiado libres_ En los templos son ellos la pie / dra del desorden y del escándalo: pues ahí no / guardan otro objeto (que el) ${ }^{38}$ de expiar, curiosear y regis / trar el semblante de las personas para alimen / tar y apacentar de esta manera con sus lascivas / miradas las pasiones de su corrompido corazón. /

En efecto, ¿no fuimos precisados nosotros en todo / tiempo, especialmente en la noche buena mo / ver sentidas quejas contra el desorden promoví / do por el oficialismo, contra sus actos imperti / nentes y atrevidos con que deshonraban à Dios / en su casa, faltaban de respeto à las personas / y les impedían de acercarse à la mesa eucarís / tica para recibir el santo de los santos? ¿No tuvi / mos por ellos que cerrar la iglesia durante las / funciones religiosas y pedir con instancias /

\section{Página 5:}

à las auctoridades civiles el restablecimiento del òrden? / ¿Y qué hicieron las auctoridades militares à quiénes / dirijimos nuestras quejas denunciando à los au / tores de los escándalos, los graduados del militaris / mo? Sonrieron, se enfadaron, se ofendieron, / no atajaron el paso a los impios libertinos y / se dieron completamente por desentendidos. Tal / es el modo con que siempre hemos visto à / ejercer la injusticia en estos dos pueblos de incre / dulidad y de tinieblas, (defraudando a los vigilantes) ${ }^{39}$, graduando à los criminales y aumentándoles el (sueldo) ${ }^{40}$. 

reunión de explotadores, ladro / nes, ignorantes, haraganes, ávidos de plata, corrup / tores è infames ultramontanos, -sin exceptuar al / señor obispo- Más aquí se me ocurre la idea / de preguntar que se ha hecho de aquel sueldo / de varios años que estaba destinado para el cape / llán dela Gobernacion del Rio Negro depuesto / arbitrariamente de su puesto y desterrado con / ánimo tan hostil. Seguramente que, como todos / piensan y muchos creen, ha sido por el dés / pota militar defraudado como fué defraudado por / cinco meses el alquiler de la casa parroquial / de Patagones convertida en hospital para 
los solda / dos enfermos, damnificado pero no indemnizado el / cura de Viedma por la ocupacion de la casa par / roquial del pueblo y la extraccion de la arena hecha / con violencia, fraude y aprisionamiento del cura del ter / reno de la iglesia_ En suma por el militarismo / en perjuicio de los misioneros salesianos todo fué / primera en 1881 / y la segunda en 1883. No recuerdo bien si fuè en / Junio ó Julio que tuvo lugar su llegada à Patagones / pero lo que es cierto su recibimiento fuè glorioso / y brillante cuanto se puede decir. Traia consigo un regimiento e soldados con banda militar / y unos trescientos indios de ambos sexos y de to / das edades medio desnudos. À la noticia de su llegada / que fuè à las once de la mañana toda la poblacion / del Carmen se precipitó al muelle entre ruidos / de música, cantos y cohetes voladores. No bien paró / el vaporcito y descendió el general à la playa se la / presentó la comisión de recepcion y luego en segui / da todos los oficiales, empleados y demás que con / él simpatizaban, quedando el resto de la poblacion / atónita contemplando el expéctáculo imponente / que se le deparaba_ Los aires se llenan de víctores / y los labios de los pretendidos elocuentes se desplegan / para ensalzar con la palabra encantadora el nom / bre del glorioso héroe argentino. Entre la multitud inmensa hacia tambien su comparicion /

\section{Página 11:}

el colegio de San José con todo el número de sus niños / guiados por sus preceptores y Don Fagnano fue el pri / mero de nosotros que fué a tributar sus homenajes al / esforzado talismán de la nación que iba dispensando / à todos con toda política sus atenciones_ Preparados los niños para cantar en su presencia el Himno na / cional y el preceptor del aula superior dispuesto / declamarle un elocuente discurso en medio / de la infinita muchedumbre, le rindieron de esta / manera el más gracioso y solemne obsequio / que se pudiera esperar y le siguieron por las calles / y plazas por donde caminaba el vencedor triunfante. / De todos puntos se ostentaban banderas flameantes: las / calles hallábanse adornadas de trofeos y la plaza rodea / da de arcos triunfales, en cuya parte superior estaba / escrito en brillantes caracteres: "salud y gloria al hé / roe de la expedicion del Nahuelhuapí, el esforzado Ge / neral Villegas. Llegado à sus habitaciones el glorioso / jefe 
seguido siempre de toda su corte y del pueblo que / à porfía le iba tributando sus homenajes de / gloria, le seguimos allá tambien con nues / tros alumnos y banda de música la que tocò las mejores /

Página 12:

piezas de su repertorio. Volvimos después de unas cuan / tas horas al colegio y à las tres de la tarde dábamos prin / cipio a los ensayos de una comedia de tres actos / que con una gracia petipieza para el fin y un bellísi / mo diálogo en honor del general teniamos prepa / rado desde un mes_Pensaba el director en prepararlo / todo para la función en nuestra misma casa como / acostumbrábamos, mas previendo la estrechez del / lugar para albergar al sinúmero de gente que acu / diera en aquelle ${ }^{47}$ circunstancia y creyendo fuera lugar / demasiado humilde para honrar à un varón tan / glorioso, pidió a Don Domingo Lopez le cediera / por una noche el gran salón que tenia a la esquina / de la plaza en donde se halla actualmente la tienda / del sol, que sería muy à propósito para la fiesta_ / Todo pues estaba concedido, ordenado y determinado / cuándo el general envía à la comisión diciendo que / todo se suspendiera, se quitara el palco, se dejara el / salón libre sin aducir razones_La noche del día / siguiente el salón ya estaba magnificamente ador / nado para una fiesta del baile, al que el general Villegas / riéndose de los frayles había acudido y permanecido /

Página 13:

toda la noche_Esta fue la indigna farsa que nos hizo, pero / que ya nos había hecho el año anterior el falso aristocrá / tico haciendo suspender (por más de un mes) ${ }^{48}$ las funciones académico teatrales que / el colegio de San José se empeñaba de representar en honor / suyo, haciéndo dar bailes todas las noches y teniendo el des / caro de convidar à semejantes tertullas à Don Costamagna / y Don Fagnano_ (... $)^{49}$ en decir que à la noche del primer / día de legada del General volvíamos a saludarle con la / banda musical en sus habitaciones permaneciendo allì / hasta las diez y media: yo asistia a los músicos y estuve / de plantón hasta aquella hora sin que nadie me dirigie / ra una palabra de atencion mientras que en las salas / un sinnumero de aduladores estaba brindando à Villegas / con vasos de escogidos licores. Tambien estaba el director / de las misiones el presbitero D. Fagnano al lado del mismo / general conversando y serian tal vez aquellos momentos / en que Villegas à pedido del sacerdote prometia de dar / al colegio de San José unos diez indios y otras tantas / indias para el colegio de las hermanas de caridad para edu / car en la religión y en las artes pero sin duda con la hi / pocrecia y falsedad con que lo habria ya prometido antes / sin efectuarlo, con el ánimo doble con que cediera à

Página 14:

Don Fagnano la casa del fuerte de la que algun tiempo / antes había dicho con Vinter que al tal frayle no le / diera ni un ladrillo_

Visto el modo en el que el general Villegas trató à / los salesianos en Patagones que con esmero le / honraban en su llegada y permanencia, veamos ahora / la inaudita crueldad con que trató à los indios reducidos. /

Eran estos, según dijimos, unos trecientos que medio des / nudos, maniatados y custodiados por los soldados en / armas fueron del muelle ${ }^{50}$ conducidos al fuerte y colocados / entre los cimientos de la nueva iglesia. Allí estu / vieron mas de un mes no teniendo por techo / más que la bóveda del cielo y sufriendo todas las intem / peries de los vientos, lluvias, frio, hambre y cuantas / miserias de que fueron suceptibles y que no hacían más / que aumentar el peso de su esclavitud_ Al ca / bo del tiempo viendo Don 
Fagnano la conveniencia / de bautizar à las criaturas y de cubrir la persona de estos / indígenas tan necesitados con un gran número de trajes / diversos traidos de Buenosaires pide el permiso / al general para llenar las dos necesidades que se lo con / cede vestidos así los indios y hecho los preparativos / diciendo que el año venidero 1888 se harà / peor difrazándose también de papa y esto en un / pueblo miserable en que con tanta paciencia, con tan / tos (.... $)^{56}$ los misioneros de la iglesia católica intentan / disipar las densas nubes del paganismo para restablecer / en su lugar la religión de JesuCristo_ Todo esto debería / recordar y mucho mas, pero mejor que yo podrá desem / peñar este cargo el director de las misiones D. Fagnano/que es perfecto conocedor de todo lo acaecido en estas / dos poblaciones del Río Negro_ 
109 Tal es pues en breve la historia por mi descrita del / militarismo en Patagonia y de la ingratitud y perseución / que por el tuvieron que sufrir los misioneros sa / lesianos en este territorio_ À pesar de todo esto nosotros ${ }^{57}$ no / nos hemos desalentado nunca en lo mas minimo / porqué quien nos guia, protege y defiende es la divina / providencia que jamás abandona à sus hijos y que / despues de dejarnos luchar contra los torbellinos / de las persecuciones suscitadas por el despotismo militar /

110 Página 18:

111 nos arranca del peligro encadenando las tempesta / des y despejando los cielos nublados y nos lleva seguros / al puerto de la salud y de la gloria.

112 Sac. Antonio Ricardi.

\section{Otras fuentes inéditas}

Archivio Salesiano Centrale

2602E1, Carta de Don Brodatto a Don Bosco, Buenos Aires, 26 de enero de 1880 y F 066, Argentina Buenos Aires-Visite Straordinarie di Pietro Ricaldone,1908.

Archivo Propaganda Fide

Volumen 14, 38-42, Lettera di don Bosco al Santo Padre, Torino, 5 aprile 1878.

Volumen 14, 92-101, Lettera di don Bosco al Prefetto al Card. Franchi, Torino 31 dicembre 1878.

Volumen 14, 714-15, Rapporto di G. Cagliero al Segretario Prefetto Propaganda Fide, 9 giulio 1884 .

Volumen 14, 701-702, Rev. Giovanni Cagliero riferisce quanto scrive il Rev Giacomo Costamagna provinciale a Buenos Aires intorno alla missione della Patagonia, Torino 8 aprile 1884 .

Volumen 14, 877-878, mons. Cagliero circa il suo arrivo nel vicariato, Carmen de Patagones, 5 ottobre 1885 .

Volumen 15, 238-239, mons. Cagliero. Relazione della visita del suo vicariato, Patagones, 28 luglio 1887.

Volumen 73, Vicariato apostolico della Patagonia Settentrionale e Centrale. Relazione per quinquenio, 1903-1908.

Archivo Salesiano Patagónico o Archivo de las Misiones Salesianas de la Patagonia Norte. Breve relación de las Misiones de la Patagonia, 2013.

Milanesio, D. (1890) Rasgos etnográficos de los indígenas de la Patagonia. Imperiosa necesidad de educarlos. Archivo Histórico de las Misiones Salesianas de la Patagonia.

Archivo Central Salesiano.

Caja 203.1. Carta de Giacomo Costamagna a D. Bosco, Patagones, 23 de junio 1879.

Fuentes éditas

Bollettini salesiani, 5 (1879); 7,9,10 (1881); 5,7 (1883).

Boletín Salesiano 8 (1895) 7 (1902) 11 (1909).

Astete, G. (1886). Catecismo de la Doctrina Cristiana, para la Arquidiócesis de la Santísima Trinidad de Buenos Aires. Buenos Aires: Colegio de Artes y Oficios.

Bosco, G y Barberis, G. (1876). La Patagonia e le Terre australi del Continente americano, [pel] sac. Giovanni Bosco. J. Borrego. Introducción y texto crítico. Ricerche Storiche Salesiane (13). 255-442.

Carbajal, L. (1900). Le missioni Salesiane nella Patagonia e regioni magallaniche. Studio storico statistico. Torino: Cavanese.

Garófoli, J. (1928). Datos biográficos y excursiones apostólicas del Rvdo. D. Domingo Milanesio, misionero salesiano. Turín: San Benigno Canavese. 
Pedemonte, L. (1943). Ceferino M Namuncurá. Testimonios. Buenos Aires: Pio IX.

\section{BIBLIOGRAFÍA}

Belza, J, Entraigas, R. Bruno, C. y Paesa, P. (1979). La expedición al desierto y los Salesianos, 1879. Buenos Aires: Don Bosco.

Belza, J. (1979). La expedición al desierto y el amanecer de las misiones salesianas patagónicas. En Belza, J. Entraigas, R. Bruno, C. y Paesa, P. (1979). La expedición al desierto y los Salesianos, 1879 (pp. 9-32). Buenos Aires: Don Bosco.

Boccara, G. (2003). Los vencedores, historia del pueblo mapuche en la época colonial. Santiago de Chile: IAM.

Boccara, G. (1999). Antropología diacrónica. Dinámicas culturales, procesos históricos y poder político. En G. Boccara y S. Galindo (Eds.), Lógica mestiza en América (pp. 21-59). Temuco: Universidad de la Frontera.

Borrego, J. (2001). La "Biblioteca Agraria Solariana" de Sevilla. Isidorianum, (10/19), 145-178.

Briones, C. (1998). La alteridad del cuarto mundo. Buenos Aires: Editorial Del Sol.

Briones, C. y Delrío, W. (2000). Patria, sí, colonias también. Estrategias diferenciadas de radicación de indígenas en Pampa y Patagonia (1885-1900). VI Jornadas Regionales de Investigación en Humanidades y Ciencias Sociales. Jujuy: Universidad Nacional de Jujuy.

Bruno, C. (1981). Los Salesianos y las Hijas de María Auxiliadora en la Argentina I, Buenos Aires: ISAG.

Copello , S. L. (1945). Gestiones del Arzobispo Aneiros en favor de los indios hasta la conquista del desierto . Buenos Aires: Coni.

Da Silva Ferreira, A. (1995). Patagonia. Realtà e mito nell'azione missionaria salesiana. Roma: LAS.

Delrío, W. (2005). Memorias de expropiación. Sometimiento e incorporación indígena en la Patagonia, 1872-1943. Buenos Aires: Editorial de la Universidad Nacional de Quilmes.

Delrío, W. (2000). El mito hacia los bordes. Construcciones del "ser aborigen" en la matriz estado-nación-territorio. Actas del VI Congreso Argentino de Antropología Social. Mar del Plata. Dumrauf, A. (1998). Pertenecen al Señor. Bahía Blanca: Archivo Histórico de las Misiones salesianas de la Patagonia II, Bahía Blanca: Archivo Histórico Salesiano de la Patagonia Norte.

Entraigas, R. (1979). Los capellanes de la expedición al desierto. En Belza, J., Entraigas, R., Bruno, C, y Paesa, P. (1979). La expedición al desierto y los Salesianos, 1879 (pp. 33-111). Buenos Aires: Don Bosco.

Fresia, I. A. (2012). Urbanizar la campaña, modernizar las costumbres. Rodeo del Medio, una villa mendocina: 1900-1915. Rosario: Prohistoria.

Navarro Floria, P. (2005). La conquista de la memoria. La historiografía sobre la frontera sur argentina durante el siglo XIX. Revista Universum, 20-21, 88-111. 
Lenton, D. (2005). De centauros a protegidos. La construcción del sujeto de la política indigenista argentina desde los debates parlamentarios (1880-1970). Tesis doctoral. Facultad de Filosofía y Letras, Universidad de Buenos Aires.

Mases, E. (2002). Estado y cuestión indígena. El destino final de los indios sometidos en el sur del territorio (1878-1910). Buenos Aires: Prometeo.

Navarro Floria, P. (2009). La conquista de la Patagonia y el reparto de las tierras. En G. Ghioldi (Comp.). Historias de las Familias Mapuche Lof Paichil Antriao y Lof Quintriqueo. Mapuche de la Margen Norte del Lago Nahuel Huapi (pp. 23-33). Villa La Angostura: Archivos del Sur.

Nicoletti, M. A. y Navarro Floria, P. (2004). Un proyecto de Coloniación italiana en Patagonia: Domenico Milanesio, sdb. y su opúsculo "Consigli e proposte agli emigranti italiani alle regioni patagoniche dell' America del Sud” (1904). Ricerche Storiche Salesiane, (45), 327-361.

Nicoletti, M. A. y Navarro Floria, P. (2004). Conflictos sobre la educación estatal y la educación católica en la Patagonia de fines del siglo XIX: análisis del discurso del inspector escolar Raúl B. Díaz. Anuario de Historia de la Educación, (5), 121-137.

Nicoletti, M. A. y Navarro Floria, P. (2002). Building an image of the indian people from Patagonia during the eihtteenth and nineteenth century: Science and Christening. En C. Briones y J. L. Lanata (Directores), Archaelogical and antropological perpectives on the Native people of Pampa, Patagonia and Tierra del Fuego to the Nineteenth Century (pp. 113-144). Wespoint/London: Bergin \& Garvey.

Nicoletti, M. A. (2005). Evangelizar y educar a los indígenas en la Patagonia: conceptos claves de Giovanni Bosco y sus misioneros salesianos (mediados del siglo XIX a principios del siglo XX). Espacios. Historia, Política y Educación, (4), 92-107.

Nicoletti, M. A. (2012). La dinámica misionera salesiana a través de la administración sacramental en la Patagonia (fines siglo XIX y principios del siglo XX), En A. Rodríguez (Comp.), Estudios de Historia religiosa (pp. 59-84). Rosario/Santa Rosa: Prohistoria.

Nicoletti, M. A. (2010). Le missioni della Patagonia da don Bosco a don Rua: situazione generale, sviluppi, bilancio. Congresso internazionale degli Studi della Congregazione Salesiana: don Michele Rua nella storia. Roma: Salesianum.

Nicoletti, M. A. (2007). La polémica en torno a la educación salesiana y la educación estatal en la Patagonia (1880-1920). En G. González (a cura di), L' Educazione salesiana dal 1880 al 1922. Istanza ed attuazioni in diversi contesti (pp. 53-71). Roma: LAS.

Nicoletti, M.A. (2007). Los Salesianos y la conquista de la Patagonia: desde Don Bosco hasta sus primeros textos escolares e historias oficiales. Revista Tefros (5, 2). Disponible en http:// www.unrc.edu.ar/publicar/tefros/revista/v5n2p07.

Noceti, R. (2012). Padre Valentín Rebok. Bahía Blanca: Inspectoría Salesiana “Ceferino Namuncurá" Argentina Sur.

Paesa, P. (1979). Los indígenas patagónicos hacia 1879 y la acción misionera salesiana. . En Belza, J., Entraigas, R., Bruno, C, y Paesa, P. (1979). La expedición al desierto y los Salesianos, 1879 (pp. 117-239). Buenos Aires: Don Bosco.

Salomón Tarquini, C. (2010). Largas noches en La Pampa. Itinerarios y resistencias de la población indígena (1878-1976). Buenos Aires: Prometeo.

Salomón Tarquini, C. (2005). “Gracias a la fe”: Misioneros franciscanos y salesianos e indígenas en la Pampa Central (1860-1930). Anuario de la Facultad de Ciencias Humanas, VI (7), pp-pp.83-98. 
Trezzi, L. (2000). Don Carlo Maria Baratta e la neo-fisiocrazia a Parma. En: F. Motto (Ed.), Parma e Don Carlo Maria Baratta (pp. 231-254). Roma: LAS.

Vanzini, M. (2001). El plan evangelizador de Don Bosco según "Las memorias de las Misiones de la Patagonia (1887-1917) del Padre Bernardo Vacchina, sdb”. Bahía Blanca: Archivo Histórico de las Misiones Salesianas de la Patagonia Norte.

\section{NOTAS}

1. Nos referimos a los Informes presentados al Colegio de Propaganda Fide que aparecen en el Epistolario de Don Bosco compilado por Eugenio Ceria y al Informe realizado con su secretario Giulio Barberis titulado La Patagonia e le Terre Australi del Continente Americano" (1876).

2. Traducción del italiano por María Andrea Nicoletti.

3. Traducción del italiano por María Andrea Nicoletti.

4. Traducción del italiano por María Andrea Nicoletti.

5. El caso paradigmático fue Ceferino Namuncurá.

6. Hemos advertido por lo menos tres diseños de Vicariato y Prefectura apostólica para la Patagonia, uno diseñado por Don Bosco en 1877 con centros en Carhué y Santa Cruz, otro por Propaganda Fide Río Colorado al Río Chubut, con sede en Carmen de Patagones o Viedma y una Prefectura Apostólica de la Patagonia Meridional desde el Río Santa Cruz a las Islas Malvinas, incluyendo la Tierra del Fuego, y el que finalmente propuso Don Bosco y se aprobó en 1884 que establecía un Vicariato apostólico en la Patagonia septentrional (Río Negro, Chubut, Neuquén), y una Prefectura apostólica en la Patagonia Meridional (Santa Cruz, Tierra del Fuego e islas Malvinas).

7. Hacia mediados del siglo XIX se entendía por misión ad gentes el trabajo misionero en "tierras paganas" y en "tierras heréticas o cismáticas" y dependía institucionalmente del Colegio de Propaganda Fide.

8. Territorio incorporado a la jurisdicción salesiana en 1896 .

9. Traducción del italiano por María Andrea Nicoletti.

10. Traducción del italiano por María Andrea Nicoletti.

11. Traducción del italiano por María Andrea Nicoletti.

12. La Patagonia quedó dividida en las siguientes vicarías foráneas: Neuquén dependiente del obispado de Cuyo; Río Negro, Chubut, Santa Cruz y Tierra del Fuego del arzobispado de Buenos Aires y La Pampa del obispado de La Plata.

13. Tanto en Italia como en España, los Salesianos desarrollaron experiencias orientadas al ámbito agrícola, a detener el éxodo rural, a dignificar el trabajo campesino, a favorecer el desarrollo de la agricultura mediante la modernización de métodos y sistemas de cultivo, a partir de cierta "idealización de la agricultura". Parma y Sevilla fueron los focos iniciales de la acción salesiana a favor de una "agricultura racional".

14. Traducción del italiano por María Andrea Nicoletti.

15. "Parece una crueldad y lo sería en otros casos, la de agarrar una criatura y quitarla a los que le han dado la vida... luego nuestra intención en querer tomar los hijos a los indios, no es para quitárselos del modo que propio y bárbaramente se ha hecho en varios puntos de la república, para separárselos y llevárselos absolutamente para que no los viesen nunca jamás; no, guárdenos Dios de tamaña crueldad! Nuestra intención es cabalmente contraria a esa, es para impedir que esto les sucediera, como a sabiendas y a nuestra vista venía sucediendo a menudo... no sólo nada tengo que reprocharme de esto, sino que al contrario muy satisfecho me veo, porque cierto estoy de haber salvado con este medio a varias criaturas que de seguro habrían sido agarradas y llevadas a costa quizá de la vida de alguno; y los parientes mismos con la luz de la pura razón 
natural llegaron a conocerlo y más tarde me lo agradecieron" (Archivo Central Salesiano, ACS, Caja 65, Memorias del P. Beauvoir).

16. El caso de Rosario Burgos vivió además otro acto de violencia al pasar a ser mujer ilegítima cuando Manuel Namuncurá fue obligado a elegir una esposa para el casamiento por la ley civil y por la Iglesia. Esta práctica también es narrada en los Boletines salesianos: "Era cosa curiosa y conmovedora los llantos y la aflicción de la mujer dejada por el indígena para casarse legítimamente con una de las dos o tres que según sus costumbres tenían" (Boletín Salesiano 7, 1902).

17. Traducción del italiano por María Andrea Nicoletti.

18. Raúl Entraigas (San Javier, Río Negro 1901-Buenos Aires, 1977) sacerdote salesiano, teólogo, miembro de la Academia Nacional de la Historia por Río Negro y Presidente de la Junta de estudios históricos rionegrinos. Escribió unas 32 obras históricas y biográficas dedicadas a la historia salesiana.

19. Pascual Paesa, (Santa María de Huerva, España 1904 - Bahía Blanca,1978), sacerdote salesiano, miembro de la Academia Nacional de la Historia por la Provincia de Buenos Aires, del Instituto de investigaciones históricas de Río Negro, de Bahía Blanca y de la Junta de Estudios araucanos. Escribió unas nueve obras de historia salesiana y argentina.

20. Cayetano Bruno, sacerdote salesiano, (Córdoba, Argentina 1912 y Buenos Aires, 2003) Doctor en derecho canónico, miembro de la Academia Nacional de la Historia y de la Junta de Historia eclesiástica argentina. Escribió numerosas obras de historia de la Iglesia y de la Congregación salesiana especialmente se destacan sus 12 volúmenes de Historia de la Iglesia y sus cuatro volúmenes de Historia de los Salesianos y de las Hijas de María Auxiliadora en la Argentina.

21. Juan Belza, sacerdote salesiano (General Pinto, Buenos Aires 1918-Buenos Aires,1888). Profesor en Letras, miembro de la Academia Nacional de la Historia por Tierra del Fuego. Autor de 16 obras dedicadas a la historia salesiana, especialmente sobre Tierra del Fuego.

22. El Boletín señala lo siguiente: "La palabra exterminio y esta distribución, contraria a las leyes y sentimientos de la naturaleza, alzaron gritos unánimes de reprobación; lamentando unos que fuesen violados los derechos y rotos los vínculos familiares, y los otros que en lugar de la Cruz se haya hecho uso de la espada no para convertir, sino para destruir a los pobres salvajes, culpables nada más que de ignorar la Religión que santifica, une y civiliza a los pueblos”. Traducción del italiano por María Andrea Nicoletti.

23. Actualmente en la Argentina, tras la división en dos inspectorías: Artémides Zatti para la zona norte, con sede en Córdoba y Ceferino Namuncurá desde Córdoba a la Patagonia, con sede en Buenos Aires; no se ha establecido aun una política de centralización de documentos. De este modo, los principales archivos siguen siendo los mencionados en las ciudades de Buenos Aires y Bahía Blanca. También debemos tener en cuenta que cada inspectoría conserva su propio archivo, que está siendo reorganizado, como los que se encuentran en las ciudades de Córdoba y Rosario.

24. La organización interna de ambos archivos difiere. En el Archivo histórico de las misiones salesianas de la Patagonia Norte en Bahía Blanca, se había iniciado una primera sistematización llevada adelante por el P. Pascual Paesa, sdb en 1978, que posteriormente continuaron Ernesto Szanto, sdb, Valentín Rebok, sdb y Vicente Martínez Torrens, sdb. Actualmente el archivo tiene un blog donde atiende consultas y publica textos y fotos http://ahmsp.tumblr.com. Allí se ha iniciado una nueva etapa de sistematización a cargo de la Profesora Pamela Alarcón. El Archivo Central Salesiano de Buenos Aires, comenzó su catalogación y ordenamiento en la década del 1980 a cargo del Padre Humberto Baratta, sdb y continuó con dos breves períodos: en la década de 1990 con el Padre Acosta, sdb y en la del 2000 por Marcos Vanzini. Actualmente se encuentra a cargo de dos hermanos coadjutores Dante Brambilla y Marino Francioni. Su organización documental se puede encontrar en la web "Historia y Religión", que remite al trabajo de Mariana 
Annecchini y Rocío Sánchez http://historiayreligion.com/wp-content/uploads/2011/11/ annecchini-sanchez-1.pdf

25. Nació en Porto Mauricio, Italia el 6 de enero de 1853 y murió en Savona el 15 de mayo de 1924 a los 71 años. Ingresó en el oratorio de Turín en 1863, novicio desde 1869, sacerdote desde 1875, pasó a ser secretario de Don Miguel Rúa, por entonces prefecto del Oratorio, cargo que luego ocuparía él. En 1885 viene a América, como secretario de Mons. Cagliero, colaboró con el Vicariato Apostólico de la Patagonia, luego fundaría la casa salesiana de Lima en Perú y sería inspector de México. Archivo Salesiano Patagónico, Breve relación de las Misiones de la Patagonia, 2013.

26. Los Bollettini Salesiani citados a lo largo del texto han sido traducidos del italiano por María Andrea Nicoletti.

27. A la palabra empleados le siguen los adjetivos "argentinos y extranjeros" tachados.

28. La palabra patagónico se escribe como un agregado.

29. Palabra sobrescrita

30. Nota al pie del original: "Resueltos de repartir mandoles si se les repartieran".

31. Agregado a posteriori.

32. Agregado a posteriori.

33. No se registra. Letra ilegible.

34. Tachado.

35. Agregado a posteriori.

36. Agregado a posteriori.

37. Agregado a posteriori.

38. Agregado a posteriori.

39. Agregado a posteriori.

40. Palabra sobrescrita.

41. Agregado al pie a posteriori.

42. Borrado.

43. Agregado a posteriori.

44. Agregado a posteriori.

45. Agregado a posteriori.

46. Referencia al P. Beauvoir.

47. Aquella

48. Agregado a posteriori.

49. No se registra.

50. Palabra sobrescrita

51. Agregado a posteriori.

52. Nota al pie del original: "Resueltos de repartir mandoles si se les repartieran".

53. No se registra.

54. También podría leerse "tendrá".

55. Nota al pie del original: "Los insultos del comandante Horma, del juez de Paz Córdoba, quienes combatió con la palabra y el escrito a los salesianos".

56. No se registra.

57. Agregado a posteriori. 


\section{RESÚMENES}

El documento "Breve relación de las misiones de la Patagonia" de 1887, también ha sido denominado por su autor, el salesiano Antonio Ricardi, como "El militarismo patagónico". El manuscrito da cuenta de los aberrantes hechos de violencia por parte del ejército argentino entre 1879 y 1883 contra los pueblos originarios de la Patagonia. En este texto, Ricardi acusa al ejército y especialmente al General Villegas de imponer en el territorio patagónico lo que él denomina "militarismo", es decir, un comportamiento inmoral, impío y anticlerical, que impidió, según su juicio, la conversión de los habitantes y la tarea evangelizadora de la Congregación Salesiana. Utiliza los términos "barbarie y civilización", identificando al primero con las acciones del ejército y al segundo con la evangelización salesiana, a la que concibe como fuente de la "verdadera civilización". Los hechos que ilustran las acciones violentas del ejército contra los pueblos originarios y las actitudes difamatorias de los militares contra los miembros de la Congregación, han sido relatados de forma homogénea sin diferenciaciones por su gravedad. Esta selección de sucesos está orientada en el documento a ilustrar quiénes son lo que impiden la tarea "evangelizadora y civilizadora" con los indígenas de la Patagonia.

The document "Brief account of the missions of the Patagonia" in 1887, has also been named by his author, the Salesian priest Antonio Ricardi, as "the patagonian militarism". The manuscript presents the aberrant acts of violence by the Argentine army between 1879 and 1883 in Patagonia. In this text, Ricardi accuses the army and especially General Villegas of imposing militarism on the Patagonian territory, i.e., an immoral and anticlerical behavior, that prevented, according to their view, the conversion of the inhabitants and the evangelization of the Salesian Congregation.

He uses the terms "barbarism and civilization", identifying the first with the actions of the army and the second with the Salesian evangelization, which he conceives as the "true civilization". The facts that illustrate these actions against the indigenous peoples and with attitudes defamatory against members of the Congregation have been reported evenly without differentiations as regards their gravity. This selection of events is aimed at proving who were the ones who impeded the "evangelizing and civilizing" of indigenous peoples.

\section{ÍNDICE}

Keywords: Evangelization, Salesians, Villegas, Patagonia

Palabras claves: Evangelización, salesianos, Villegas, Patagonia

\section{AUTORES}

\section{MARÍA ANDREA NICOLETTI}

Instituto de Investigaciones en Diversidad Cultural y Procesos de Cambio - Universidad Nacional de Río Negro, Consejo Nacional de Investigaciones Científicas y Técnicas, Argentina Correo electrónico: mariaandreanicoletti@ gmail.com 


\section{IVÁN ARIEL FRESIA}

Centro de Investigaciones Históricas, Facultad de Filosofía y Letras, Universidad Nacional de Córdoba, Argentina

Correo electrónico: arielfresia@hotmail.com 